\title{
Tobacco control in Europe: progress and key challenges
}

\author{
Marc C Willemsen (1) , 1,2 Ute Mons (1) , 3,4 Esteve Fernández (1) 5,6,7,8
}

${ }^{1}$ Health Promotion, Maastricht University Faculty of Health Medicine and Life Sciences, Maastricht, The Netherlands ${ }^{2}$ Netherlands Expertise Centre for Tobacco Control (NET), Trimbos Institute, Utrecht, The Netherlands

${ }^{3}$ Cancer Prevention Unit, Heidelberg, Germany ${ }^{4}$ Faculty of Medicine, University of Cologne and University Hospital Cologne, Cologne, Germany

${ }^{5}$ Tobacco Control Research Group, Epidemiology and Public Health Programme, Institut d'Investigació Biomèdica de Bellvitge (IDIBELL), L'Hospitalet de Llobregat, Spain

${ }^{6}$ Tobacco Control Unit, WHO Collaborating Center for Tobacco Control, Institut Català d'Oncologia (ICO), L'Hospitalet de Llobregat, Spain ${ }^{7}$ School of Medicine and Clinical Sciences, Universitat de Barcelona, Barcelona, Spain

${ }^{8}$ Centro de Investigación

Biomédica en Red

Enfermedades Respiratorias (CIBERES), Instituto de Salud Carlos III, Madrid, Spain

\section{Correspondence to}

Professor Marc C Willemsen Health Promotion, Maastricht University Faculty of Health Medicine and Life Sciences, 6200 MD Maastricht, The Netherlands;

marc.willemsen@

maastrichtuniversity.nl

Received 18 June 2021

Accepted 27 September 2021

Check for updates

(C) Author(s) (or their employer(s)) 2022. No commercial re-use. See rights and permissions. Published by BMJ.

To cite: Willemsen $\mathrm{MC}$,

Mons U, Fernández E.

Tob Control

2022:31:160-163

\section{ABSTRACT}

We discuss progress made with respect to reducing the burden of disease caused by tobacco use within the WHO European Region and outline major issues and challenges regarding ongoing implementation of tobacco control policy. Although 50 of 53 countries in the WHO European Region are parties to the WHO Framework Convention for Tobacco Control (FCTC), smoking prevalence varies tremendously between European countries. While smoking rates are decreasing slowly, faster declines among smokers with a higher socioeconomic status are leading to growing inequalities in tobacco use. Governments in Europe increasingly formulate visions of 'tobacco-free' societies and it is encouraging that the European Commission aims to achieve a tobacco-free Europe in 2040 as part of its Europe's Beating Cancer Plan. While core WHO FCTC measures still have to be fully implemented in many European countries, some countries are implementing more advanced measures such as plain packaging, banning of characterising flavours from tobacco products, tobacco retailer licensing and extensions of smoking bans into spaces such as cars, outdoor areas and public streets. Remaining challenges include protecting tobacco control policymaking from tobacco industry interference, insufficient dedicated budget for scientific research and the need for Europe-wide monitoring data on use of tobacco and nicotine products.

\section{INTRODUCTION}

The WHO European Region comprises 53 countries. To date, with the exception of Liechtenstein, Monaco and Switzerland, all WHO European Region countries, including the European Union (EU), are parties to the WHO Framework Convention for Tobacco Control (FCTC). Despite this, the European Region has one of the highest proportion of premature deaths due to tobacco use in the world, while smoking prevalence declines at a relatively slow rate compared with other WHO regions, particularly among women. ${ }^{1}$ According to WHO estimates, the proportion of deaths from non-communicable diseases attributable to tobacco use in Europe was $18 \%$ in 2015 , meaning that almost one in every five of deaths from non-communicable diseases could be avoided if tobacco use was eliminated altogether from the region. ${ }^{2}$ As exemplified for lung cancer in a recent modelling study, implementation of evidence-based tobacco control policies at the most comprehensive level could considerably reduce the smoking-attributable disease burden across Europe. ${ }^{2}$

\section{Trends in smoking prevalence}

Within the European Region, differences between countries are tremendous, with current male smoking prevalence, for example, varying from nearly $60 \%$ in the Russian Federation to around $16 \%$ in Iceland in $2015 .^{3}$ Overall, smoking prevalence (male and female combined) tends to be highest in Central and Eastern European countries, and lowest in the Nordic countries and in Central Asia (Uzbekistan, Azerbaijan). Overall, smoking rates are decreasing only slowly and projections suggest that half of the countries of the WHO European Region will not reach the global target of $30 \%$ tobacco-use prevalence reduction between 2010 and 2025. ${ }^{3}$ Besides smoking prevalence on average being nearly twice as high among men than women, there are also apparent disparities in smoking in relation to socioeconomic status (SES) with consistently higher smoking prevalence among people with lower SES across the European Region. ${ }^{3}$ As several studies indicated disproportionally faster declines among smokers with a higher socioeconomic position in European countries, relative inequalities appear to have widened in recent years, ${ }^{45}$ and are projected to increase further. ${ }^{3}$ Thus, accelerating the decline of smoking among all population groups should continue to be a high priority in Europe. ${ }^{6}$

\section{Variation in adoption of tobacco control}

The adoption and implementation process of tobacco control policies has varied widely across European countries, that is, in strength of policies, the timing of implementation and level of enforcement. ${ }^{7}$ The Tobacco Control Scale (TCS) monitors the implementation of tobacco control policies at country level across Europe. ${ }^{8}$ The TCS is based on the six cost-effective interventions listed by the World Bank and ranks countries according to their total score. ${ }^{9}$ So far, there have been six editions (2005, 2007, 2010, 2013, 2016 and 2019). The policy domains and corresponding scores have slightly varied across consecutive editions, but the total maximum score (100) remained the same. As illustrated by the comparison of TCS scores from 2007 and 2019 (figure 1), countries with scores above 50 in 2007 but which failed to undertake new initiatives fell in their ranking (Sweden, Malta, Belgium, Italy, Estonia, Bulgaria, Poland). A few countries scoring less than 50 in 2007 (Hungary, Portugal, Slovenia, Greece and Austria) advanced to a score above 50 in 2019. It should be noted however that the TCS scores are published every 3 years, so that most recent improvements in tobacco control policies are not yet captured. For example, Belgium and the Netherlands have 


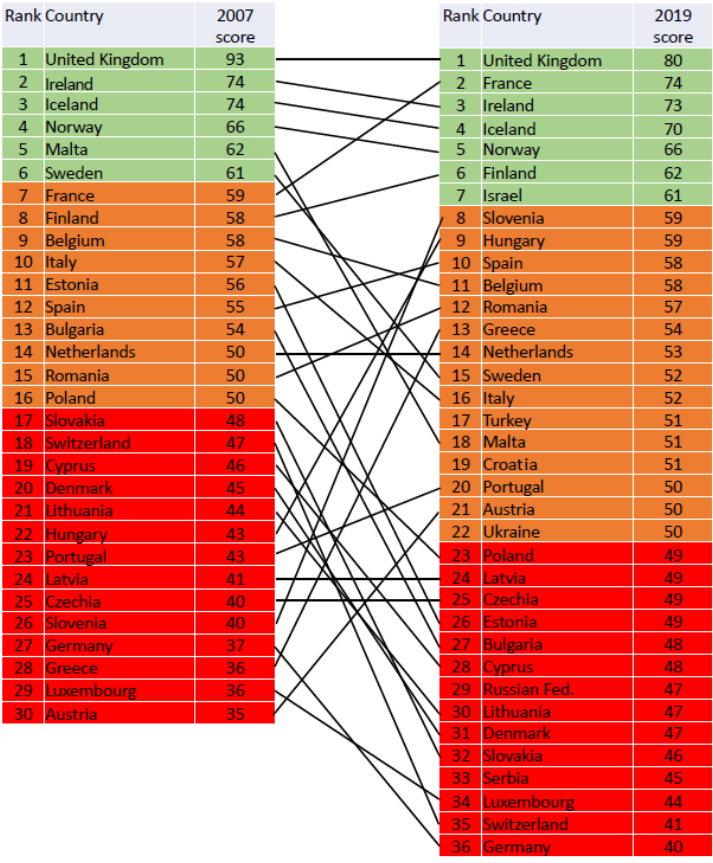

Figure 1 European countries' ranking and scores on the Tobacco Control Scale, editions 2007 and 2019.

implemented important new measures after data collection for the 2019 TCS was completed. The countries leading in 2019 in Europe are those that were already pioneering in 2007 (UK, Ireland, Iceland, Norway, Finland), and which have implemented comprehensive tobacco control policies in more recent years, including price increases and plain packaging.

\section{'Tobacco-free society' ambitions}

The EU sets tobacco control standards for the European region and beyond, through trade agreements with other parts of the world and through its important role in the WHO FCTC Conferences of the Parties. The EU has recently also formulated the vision of achieving a tobacco-free Europe, where less than $5 \%$ of the EU population uses tobacco in 2040, as part of Europe's Beating Cancer Plan. ${ }^{10}$ An increasing number of EU member states formulate visions of a tobacco-free society, in combination with concrete roadmaps and policy goals. The European Network for Smoking and Tobacco Prevention (ENSP) defined a 'tobacco-free' society as one in which prevalence of tobacco smoking is below 5\%. ${ }^{11}$ Individual countries vary regarding the target date, with Finland ${ }^{12}$ and the Netherlands ${ }^{13}$ aiming for 2040 , while England aims to be tobaccofree by $2030,{ }^{14}$ Scotland by $2034,{ }^{15}$ France by $2032^{16}$ and the Irish Republic even by $2025 .^{17}$

\section{Policymaking in the EU}

As key policymaking bodies (representing 27 of 53 countries in the WHO European region), the European Commission (EC), the European parliament and the Council of Europe play significant roles in European tobacco control. Although the EU's competence to issue legally binding measures in the field of public health is limited, the role it plays in European tobacco control should not be underestimated and is growing. ${ }^{18}$ However, its role remains complex, because of principles of subsidiarity and proportionality to which the EU must comply.
Member states have unique national policy contexts, so that compromises at the EU level are inevitable-and worrying, particularly given the influence of tobacco industry at national level, particularly in Germany, Austria, Greece, Hungary, Romania, Poland, and the Czech Republic. ${ }^{19}$

The EU's main legislative acts are so-called directives (next to other types of legal acts, such as regulations, decisions and recommendations). ${ }^{20}$ Key EU tobacco control laws are the EU Tobacco Tax Directive (2011/64/EU) and the EU Tobacco Products Directive (2014/40/EU) including its additional implementing and delegated acts, which are currently undergoing an evaluation and review launched by the EC's Directorate-General for Health and Food Safety in 2020. The Tobacco Products Directive is also evaluated through the Joint Action on Tobacco Control Project, especially regarding barriers to implementation of the directive, including the regulation of novel and emerging products, with funding from the EU's Health Programme. ${ }^{21}$ With the tax directive, the EU attempts to harmonise taxes across the internal market by setting minimum taxation levels. This has led to higher prices in southern member states and in those that joined the EU in $2004 .^{22}$ However, remaining price differentials between member states lead to significant cross-border flows of cigarettes from low-tax to high-tax countries, undermining the effectiveness of national taxation. The EU Tobacco Advertising Directive (2003/33/EU) would also warrant revision, as tobacco industry marketing to young people through social media is currently not adequately addressed. Furthermore, advertising and promotion at the point of sale is also not addressed, as the EU has no power to adopt binding legislation on advertising that does not have a cross-border aspect.

\section{Current and novel policy measures}

While many European countries are still struggling to fully implement core WHO FCTC measures, others consider or implemented more innovative measures.

Within the EU, the EU Tobacco Product Directive (TPD) has resulted in 28 European countries having mandatory pictorial warnings on cigarette packs (covering $65 \%$ of the front), with an increasing number of countries taking this one step further by requiring plain packaging, ${ }^{7}$ including some European countries outside the EU (Turkey, Israel, Norway). ${ }^{23}$ The TPD also comprises an EU-wide track-and-trace system to combat illicit trade and bans characterising flavours from traditional tobacco products. In addition to the current 27 EU member states, the UK, Moldova and Turkey have similar policies to ban characterising flavours. ${ }^{24}$

Finland, Hungary, France, Italy and Spain have implemented retailer licensing, although only Finland and Hungary for public health reasons-to control the density of tobacco venues.

Promoting the use of electronic cigarettes as a public health strategy is limited to the UK, consistent with its historically high use of nicotine substitutes. ${ }^{25}$

Many countries are extending smoking bans beyond indoor public and workplaces, such as in private $\operatorname{cars}^{26}$ and in outdoor areas such as parks (for example, France: Strasburg), beaches (Italy: Bibione; Wales: Pembrokshire; Spain: many regions), and public streets (UK: Bristol; Netherlands: Amsterdam).

\section{Remaining challenges}

Implementation of tobacco control measures is especially lagging behind in Eastern European countries. ${ }^{27}$ The gap 
between West and East continues to exist, and might even widen further since tobacco industry presence shifts from countries in Western Europe such as the Netherlands and the UK to Eastern countries which provide relatively cheap labour for tobacco manufacturing and tend to have less restricted regulatory environments. ${ }^{28}$

Effective protection of tobacco control policymaking from the tobacco industry as mandated by Article 5.3 WHO FCTC ${ }^{6}$ remains a major challenge as no more than one-quarter of 47 European countries reported to have implemented this partially. ${ }^{29}$

Another major challenge is insufficient budget for and coordination of scientific research and lack of Europe-wide comparable monitoring data. Countries with a less favourable political environment and less budget for tobacco control research are struggling most to implement FCTC measures. Even the EC gives hardly any support to build capacity in countries with weak tobacco control infrastructures and does not provide a sufficient financial basis for tobacco control research. For example, as part of the landmark EU4Health Programme, the EC announced that it will discontinue the operating grant mechanism for public health Non-Governmental Organisations (NGOs) capacity building in Europe. ${ }^{30}$

Data on national trends in smoking either come from infrequent and incomparable national representative samples or are drawn from infrequent Eurobarometer surveys, which are not set up to provide reliable estimates of country-level smoking prevalence. ${ }^{31}$ Regardless of the value of these cross-sectional surveys to learn about the tobacco momentum, tobacco control in Europe would benefit from prospective longitudinal studies among representative population samples, for example, following the model of the PATH Study. ${ }^{32}$

\section{Concluding remarks}

The slow process of European policymaking lags behind tobacco industry innovations in product development, marketing and sale. The industry easily adapts to and anticipates sluggish improvements of the regulatory environment. Countries in the European region observe EU initiatives, as the EU sets examples for the wider region. It is therefore encouraging that the EC has announced to strengthen existing regulatory instruments to achieve a tobacco-free Europe in 2040 as part of the new Europe's Beating Cancer Plan. ${ }^{70}$ Modelling studies could help in providing data on whether current and potential future tobacco control measures are sufficient to reach the 2040 smoke-free goals and could inform tobacco control policymaking not only in European countries but also at the EU level. A concrete roadmap to achieve a tobacco-free Europe in 2040, as well as the provision of sufficient funding

\section{What this paper adds}

- This contribution discusses the progress of tobacco control within the WHO European Region.

- European governments increasingly formulate visions of 'tobacco-free' societies, including the European Union.

- Many European countries, especially in Eastern Europe, are still struggling with implementing basic WHO Framework Convention for Tobacco Control measures.

- Main challenges are protecting tobacco control policymaking from tobacco industry interference and insufficient dedicated budget for research and monitoring. and support for tobacco control research, monitoring and implementation and political leadership are now required to bring the vision to life.

\section{Twitter Marc C Willemsen @Marc_Willemsen and Esteve Fernández @stvfdz}

Acknowledgements We thank Ranti Fayokun (WHO), Armando Peruga (IDIBELL), Charlotta Pisinger (CKFF), Cornel Radu Loghin (ENSP) and Kerstin Schotte (WHO) for their helpful comments on the manuscript. EF thanks CERCA Programme/Generalitat de Catalunya for institutional support.

Contributors MCW, UM and EF drafted the manuscript. All authors critically revised the manuscript and approved the final manuscript version.

Funding $E F$ is partly supported by the Ministry of Business and Knowledge from the Government of Catalonia (2017SGR319). UM is supported by the Marga and Walter Boll Foundation.

Competing interests None declared.

Patient consent for publication Not required.

Provenance and peer review Commissioned; externally peer reviewed.

\section{ORCID IDs}

Marc C Willemsen http://orcid.org/0000-0001-9387-592X

Ute Mons http://orcid.org/0000-0003-1764-6783

Esteve Fernández http://orcid.org/0000-0003-4239-723X

\section{REFERENCES}

1 WHO. WHO global report on trends in prevalence of tobacco smoking 2000-2025, second edition. Geneva: Wold Health Organization, 2019.

2 Gredner T, Mons U, Niedermaier T, et al. Impact of tobacco control policies implementation on future lung cancer incidence in Europe: an international, population-based modeling study. Lancet Reg Health Eur 2021;4:100074.

3 WHO. European tobacco use: trends report 2019. Copenhagen: World Health Organisation, 2019.

4 Bosdriesz JR, Willemsen MC, Stronks K, et al. Socioeconomic inequalities in smoking cessation in 11 European countries from 1987 to 2012. J Epidemiol Community Health 2015:69:886-92.

5 Giskes K, Kunst AE, Benach J, et al. Trends in smoking behaviour between 1985 and 2000 in nine European countries by education. J Epidemiol Community Health 2005;59:395-401.

6 Peruga A, López MJ, Martinez C, et al. Tobacco control policies in the 21st century: achievements and open challenges. Mol Oncol 2021;15:744-52.

7 European Commission. Report from the Commission to the European Parliament, the Council, the European economic and social Committee and the Committee of the regions on the application of Directive 2014/40/EU concerning the manufacture presentation and sale of tobacco and related products. Brussels: European Commission, 2021.

8 Joossens L, Raw M. The tobacco control scale: a new scale to measure country activity. Tob Control 2006;15:247-53.

9 Joossens L, Feliu A, Fernández E. Tobacco control scale: monitoring the implementation of tobacco control policies systematically at country-level across Europe Brussels: association of European cancer Leagues, Catalan Institute of oncology, 2020. Available: www.tobaccocontrolscale.org [Accessed 2 Jun 2021].

10 European Commission. Europe's beating cancer plan. Brussels: European Commission, 2021.

11 Starchenko P. Tobacco-Free Europe: meeting new challenges, driving to tobacco endgame (Athens Declaration), 2017. Available: http://ensp.org/2017/05/31/athensdeclaration/

12 Ministry of Social Affairs and Health. Roadmap to a tobacco-free Finland: action plan on tobacco control. Helsinki: Ministry of Social Affairs and Health, 2014.

13 Van Mourik D-JA, Willemsen MC. Netherlands: National Prevention Accord to improve health and reduce smoking [blog]. Tob Control 2019;28:126.

14 Branston JR, Arnott D, Gallagher AWA. What does Brexit mean for UK tobacco control? Int J Drug Policy 2021;92:103044.

15 Scottish Government. Creating a tobacco-free generation: a tobacco control strategy for Scotland. Edinburgh: Scottish Government, 2013.

16 French Ministry of Solidarity and Health. Priorité pr'vention: Rester en bonne santé tout au long de sa vie - Programme National de lutte contre le tabac 2018-2022. Paris: Ministère des Solidarités et de la Santé, 2018.

17 Department of Health. Tobacco policy review group. tobacco free Ireland. Dublin, 2013. Available: https://health.gov.ie/wp-content/ [Accessed 13 Mar 2021].

18 Alemanno A, Garde A. The emergence of an EU lifestyle policy: the case of alcohol, tobacco and unhealthy diets. Common Mark Law Rev 2013;50.

19 Assunta M. Global tobacco industry interference index (global tobacco index). Bangkok: Global Center for Good Governance in Tobacco Control (GGTC), 2020. 
20 European Commission. Types of EU law. Brussels: European Commission, 2021. Available: https://ec.europa.eu/info/law/law-making-process/types-eu-law_en [Accessed 24 Sep 2021].

21 JATC. Joint action on tobacco control. Athens: Hellenic cancer Society, 2021. Available: https://jaotc.eu/ [Accessed 24 Sep 2021].

22 ASPECT consortium. Tobacco or health in the European Union: past, present and future. Brussels: European Commission, 2004.

23 Campaign for Tobacco-Free Kids. Standardized or plain tobacco packaging: international developments Washington: campaign for tobacco-free kids, 2021. Available: https://www.tobaccofreekids.org/assets/global/pdfs/en/standardized_ packaging_developments_en.pdf [Accessed 14 Jul 2021].

24 Erinoso O, Clegg Smith K, lacobelli M, et al. Global review of tobacco product flavour policies. Tob Control 2021;30:373-9.

25 Berridge V, Hall W, Taylor S, et al. A first pass, using pre-history and contemporary history, at understanding why Australia and England have such different policies towards electronic nicotine delivery systems, 1970s-c. 2018. Addiction 2021;116:2577-85.

26 Campaing for Tobacco-Free Kids. Tobacco control laws: legislation: campaign for tobacco-free kids, 2021. Available: https://www.tobaccocontrollaws.org/legislation [Accessed 17 Mar 2021].
27 Bafunno D, Catino A, Lamorgese V, et al. Tobacco control in Europe: a review of campaign strategies for teenagers and adults. Crit Rev Oncol Hematol 2019;138:139-47.

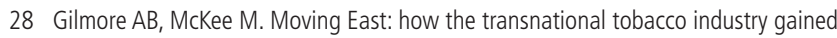
entry to the emerging markets of the former Soviet Union-part II: an overview of priorities and tactics used to establish a manufacturing presence. Tob Control 2004;13:151-60.

29 Glahn A, Kyriakos CN, Loghin CR, et al. Tobacco control achievements and priority areas in the who Europe region: a review. Tob Prev Cessat 2018;4:15.

30 EPHA. The EU4Health 2021 Work Programme: a missed opportunity to support European health NGO's to play their key role in the COVID-19 pandemic and beyond: European Public Health Alliance (EPHA), 2021. Available: https://epha.org/theeu4health-2021-work-programme-a-missed-opportunity-to-support-european-healthngos/ [Accessed 7 Jul 2021].

31 Britton J, Bogdanovica I. Tobacco control efforts in Europe. Lancet 2013;381:1588-95.

32 Hyland A, Ambrose BK, Conway KP, et al. Design and methods of the population assessment of tobacco and health (path) study. Tob Control 2017;26:371-8. 